\title{
Cultural Heritage in the Realm of the Commons: Reading a Letter from the Future
}

\author{
Stelios Lekakis
}

He filled the glasses and raised his own glass by the stem.

'What shall it be this time?' he said, still with the same faint suggestion of irony.

'To the confusion of the Thought Police?

To the death of Big Brother?

To humanity? To the future?'

'To the past,' said Winston.

'The past is more important,' agreed O'Brien gravely.

G. Orwell, 1984

There is a lingering idea that the reader of the commons often stumbles upon in the bibliography; it suggests that in recent years we have been pondering over the definitions and the nature of the commons because their status is increasingly challenged and their existence compromised by emergent threats prescribing enclosures for goods and services up until now enjoyed freely.

This idea could imply two things: that we might take some goods for granted, becoming uneasy only when they fall out of reach or, conversely, that we might - just recently - be becoming aware of the increasing rate of privatisation

How to cite this book chapter:

Lekakis, S. 2020. Cultural Heritage in the Realm of the Commons: Reading a Letter from the Future. In Lekakis, S. (ed.) Cultural Heritage in the Realm of the Commons: Conversations on the Case of Greece. Pp. 1-14. London: Ubiquity Press. DOI: https:// doi.org/10.5334/bcj.b. License: CC-BY 
processes spread by neoliberal politics, enclosing and capitalising on goods such as public space, seeds, software and information but also politics, democracy, personal or communal relationships and other aspects of our culture.

Cultural heritage might be a paradigmatic category for both arguments. Invented in the realm of nation-states, from an early point it was considered a public asset, stewarded to narrate the historic deeds of the ancestors, on behalf of their descendants; As the neoliberal narrative would have it, it is for the benefit of these tax-paying citizens that privatisation logic on heritage sector have been increasing over recent decades, to cover their needs in the name of social responsibility and other truncated views of the welfare state.

This volume examines whether we can place cultural heritage at the other end of the spectrum, as a common good and potentially as a commons. It does so by looking at Greece as a case study, lately a battlefield of harsh and experimental austerity measures but also of inspiring grass-roots mobilisation and scholarship, currently blossoming to defend the right of communities to enjoy, collaboratively manage and co-create goods by the people, for the people. Since cultural heritage - and culture in general - is hastily bundled up with other goods and services in various arguments for and against their public character, this volume invites several experts to discuss their views on their field of expertise and reflect on the overarching theme: Can cultural heritage be considered a commons? If so, what are the advantages and pitfalls concerning theory, practice and management of heritage? What can we learn from other public resources with a longer history in commons-based or market-oriented interpretation and governance? Can a commons approach allow us to imagine and start working towards a better, more inclusive and meaningful future for heritage?

\section{Genealogies of the commons}

When using the term commons, we are normally referring to the historic common land enclosures in Britain from the $16^{\text {th }}$ and $17^{\text {th }} \mathrm{c}$. onwards and how these processes contributed to a number of revolutionary changes in the European agricultural and social landscape, mainly facilitating the 'primitive capital accumulation' in favour of the emerging bourgeoise. Land enclosures and capital accumulation were constitutive elements in the transformation from feudalism to capitalism and a catalyst for the deterioration of the living conditions and labour potential of small farmers, who had until that point based their survival on customary use rights of the land and the relevant arrangements (Rodgers et al. 2011; Zuckert 2012).

However, apart from the Marxist exegesis as the prerequisite for the (re)production of the capitalistic frame, the commons actually has a longer history (De Angelis 2017). Perhaps the earliest definition of the common good (koinón) can be traced back to Aristotle, where in the context of the city-state (pólis), participatory citizen action was needed to deliberate a shared and just communal life. Again, as a civic duty for the common benefit (koinó symphéron / utilitas 
communis), we find it in the Roman law, to explicitly demarcate the inherently inalienable goods (res communes), such as the air, running water, the sea and the seashore (Menatti 2017: 650). This Latin definition, where the word derives from (munus: obligation \& gift) precisely documents the reciprocal core of the term community (cum-munus) and reflects the collective attempt to sustain a group of people on shared grounds (Dardot \& Laval 2019: 9-15). These three elements can be considered as the main constituents of the commons: i.e. the resources at hand, the communities in charge and the regulatory frames to sustain this management system.

\section{Contemporary approaches on commons' theories}

In this volume the same tripartite schema comes up quite often; Interested communities collaborate on the protection and (re)production of a resource or a service, following agreed regulations for the shared interest; people collaborate, they common in bottom-up, inclusive, just and synergetic ways to produce use value for them and the rest of the people (Dellenbaugh et al. 2015; Linebaugh 2008: 279). The goods produced are left as a patrimony in material or immaterial forms; for example, seed stock, food, cultural systems, management circuits or open-source software. This open-ended interpretation makes classification of the commons both complex and versatile, depending on the resource (material, immaterial, (non)renewable, natural, manmade), the scale (local, regional, national, global), the context (social, cultural, academic) and the enclosure risks (public / private) (Bollier 2014).

Whatever the taxonomic arrangement, commons are better known in the bibliography from Hardin's (1968) paper on the ascertained tragedy in their management, a neoclassical argument that has since been systematically challenged and overthrown as referring to an exploitative, individualistic, antagonistic management steeped in the contemporary market ethos of unregulated, uncontextualized, freely accessible resources, ${ }^{2}$ approached by people of the Homo Economicus subspecies, i.e. solely interested in their own profit (Olsen 1965; Caffentzis \& Federici 2014).

Hardin's approach was particularly criticised by the - only woman - Nobel Prize laureate in Economics, Elinor Ostrom, in her book: Governing the Commons: The Evolution of Institutions for Collective Action. Ostrom's lifelong project focuses on the collective management of Common Pool Resources (CPR), natural or man-made resource systems that are subtractable and pose difficulties in excluding potential beneficiaries from obtaining benefits from their use (Ostrom 1990: 30). Although regularly criticised for the (new

${ }^{2}$ Hardin's work has contributed to the popularisation of a usual mistake in the discussion of the commons, sometimes solely associated with common goods, i.e. open access resources, indeed susceptible to overuse if no other conditions apply. 
institutional) economistic approach (De Angelis 2017), Ostrom's contribution $^{3}$ attracted a great deal of attention to the field and opened up new horizons in the study of the commons, particularly in relation to the abundant and diverse cultural systems and social interactions of traditional communities that formulate sustainable strategies for land use, crop collection, cultivation differentiation and natural resources management (Ostrom 1990: 88-101). Her work supported several systematic and transdisciplinary approaches to the socio-economic and ecological system of commons, developed in different areas from the 1980s onwards, mostly related to natural resources (animal husbandry, fisheries, forestries, water management, irrigation systems), political studies and economics (van Laerhoven \& Ostrom 2007: 3-7).

Ostrom's work resonates in the contemporary discussion of the commons, however in this volume authors are inspired from manifold theories and practices developed since, deriving among others from political theory, law, organisational studies, traditional knowledge, political economy and the proliferation of social movements worldwide.

\section{Re-inventing the commons: The political and the digital}

From the 1990s onwards, a diverse group of thinkers and researchers broadened our understanding of the commons, linking in with the rich tradition of political approaches such as Proudhon's mutualism, Bakunin's collectivism, Ricardian and Utopian socialism or drawing on the works of Arendt, Castoriadis and Chomsky, in political economy arguments cutting across production, dissemination and consumption of resources, community organisation, urban and rural life et al.

In later years, a reformist and a radical approach could be discerned, although definite categorization should be avoided (Papadimitropoulos 2017: 566). Thus, we could discuss a 'pragmatic' school of thought (for example, Bauwens, Bollier, Kostakis, Arvidsson \& Peitersen, Papanikolaou) that negotiates with the traditional statecraft, proposing and building an alternative paradigm in the shell of the old world (see for example, the concepts of the 'partner state' and the 'chamber of the commons'). This extends to the upcoming Social Economy practice; a diverse bundle of services, products and actors, prioritising social objectives over profit maximisation. On the other hand, a more 'radical', neo/autonomist Marxist approach can be observed, suggesting the assemblage of counter-power for constitutive change (for example, De Angelis, Stavrides, Caffentzis, Federici, Rigi, Kioupkiolis). This approach can be related to calls for egalitarian, action-focused shareholder formations, promoting Solidarity Economies outside and against the capitalistic frame.

\footnotetext{
${ }^{3}$ See 'The International Association for the Study of the Commons' (https:// iasc-commons.org).
} 
With the dawn of the new millennium, the spread of the Internet and new digital technologies enacted pioneering patterns of association and selfgovernance, reinventing and expanding the commons as a mode of co-creation and social sharing in the digital field, outside the traditional limits of forests and grazing grounds. As a response and a probe, a large body of theoretical knowledge has been developed 'on digital commons', coupled with practical applications, spanning software development (Linux, Apache HTTP Server), online encyclopaedias (Wikipedia) and social media platforms (Benkler 2006: 117-120; Bollier 2008: 2-4; Bauwens \& Niaros 2017). This form of commons-based peer-governance and production in the digital realm holds a prefigurative promise, and enables the proliferation of decentralized communities, with their own (im)material output, against platform capitalism and the omnipresent aspect of the extractive digital economy (Kostakis et al. 2019; Benkler 2006; Anastasopoulos this volume; Tsiavos this volume).

However, commons have also been physically present in more radical ways. They feature in various protesting platforms around the world against neoliberal appropriation of resources, state violence and democracy enclosures: from the 1970s ecological movements to the Chipko Andolan in India, the Landless Workers' Movement in Brazil, the Zapatistas movement in Chiapas, the Water wars in Cochabamba, the Occupy movement and its spill over effects on the Square movements at the beginning of the 2010s (Gezi Park Istanbul, Syntagma Square Athens, Puerta del Sol Madrid, Tahrir Square Cairo, Bouazizi Square Tunisia) and the recent 'municipalist' politics in Spain and Italy. Following different trajectories, these movements make commoning incremental to the emergence of a new historical paradigm, a democratic and caring culture that helps us prefigure politics beyond the normalised capitalist hegemony and statist socialism (Caffentzis \& Federici 2014; Kioupkiolis this volume; Markopoulos this volume).

Even if it is difficult - if not impossible - to compile a solid or linear genealogy, commons emerge as an all-encompassing theoretical and practical process in communities across the physical and the digital realm, charged politically but not necessarily ideologically, holding the promise of a more egalitarian and sustainable future. To understand this multifaceted phenomenon, university courses and modules on commons are growing across the world, related to law, environment, governance and Social \& Solidarity Economy. Lately arguments are spilling over to thematics as intellectual property, digital information, traditional knowledge, biodiversity and genetic material, urban life, gender and alternative economies (Bollier 2003; Scharper \& Cunningham 2006; Kanellopoulou this volume; Harvey 2016; Federici 2012; Gibson et al 2013).

\section{Cultural heritage as a commons: The research field}

In this emerging scientific arena of debate and practice, culture and heritage appear in notably few discussions while the current available bibliography can 
be considered rather fragmented in terms of theoretical enquiries and applications (Lekakis et al. 2018).

Cultural commons are broadly interpreted as cognitive/intellectual commons, involving concepts as social structures, regulatory frames and processes of commoning, along with their immaterial outputs (Hess 2012: 25; Bertacchini et al. 2012). In this pluralistic but opaque approach, cultural commons reflect a number of values and include such diverse goods as ethics, languages, codes, symbols, rites, customs, information, traditional knowledge, but also the creative aura of a cultural district or the collaboration patterns between online peers over the production of open-source software (Benesch et al. 2015). On the other hand, treating them as "new commons", may pinpoint their vulnerability (enclosures, overuse, social dilemmas) and the need for a governance system (Hess 2008). It does not however ameliorate their under-theorisation or encourage further exploration in terms of meanings, boundaries and affordances. On the contrary, it may act as a pretext to the distortion of the goods and practices involved, i.e. their economistic appreciation or even marketisation through impact assessment models.

Heritage commons appear in the bibliography even less frequently, mainly inferred through discussions in heritage theory (values, tangible-intangible resources, indigenous heritage), community inclusion, institutions \& management (public / private, ownership, rights), criticism to economic development \& sustainability practices (tourism, management) (Gould 2017). When explored, heritage commons are regularly presented as similar to environmental commons or considered as cultural commons, a treasury of the community's imagined identity, part of the aspired and yet utopian democracy of the commons (Bollier 2016; Lieros 2016: 232). In some instances, they are idiosyncratically conceptualised or examined in very specific hypotheses and case studies (Erickson 1992; Benesch 2016; Gonzalez 2014), inadequately theorised or approached through economistic viewpoints (Bertacchini et al. 2012) but rarely treated as a container of values, worthy of meticulous research to better understand local, regional and global identities but also inform potential arrangements for their viable management (Catapoti et al. this volume; Dragouni this volume).

\section{Case study and scope of the volume}

As mentioned earlier, this volume invites a number of experts to converse on heritage commons, from their own standpoint and field of expertise (environmental, digital, urban, political, cultural resources and processes of governance and production) that in many cases has a longer history on the commons front; an interdisciplinary research question that developed out of a session in the 2015 Dialogues in Archaeology Conference. Their approaches depart either from the 'reformist', the 'radical' school of thought or somewhere in the middle, shifting between academic and/or on-the-ground perspectives, tangible 
and intangible resources, broader and theoretical to narrower and practical contexts (for example, national politics vs neighborhood dynamics) but also ontological, political, economic and managerial considerations in an attempt to raise key issues and map this newly constituted field without though prescribing a canonical model of heritage (commons). Providing the latter is beyond the scope of this exploratory volume.

Geographically, the volume focuses on Greece, reflecting on the lingering narratives of economic crisis (2010-2017). Nowadays, it is largely admitted that the austerity measures, a result of the Greek government-debt crisis, brought about an incipient disintegration of the welfare state, a desert of unmet social needs and relentless neoliberal restructuring of provisions, job precarity and increased unemployment rates but also the rise of new forms of nationalist and neo-fascist movements that settled into the political scene (Bekridaki \& Broumas 2016: 233; Bloemen \& De Groot 2019). Alongside summer tourism, the sun, Zorba the Greek, souvlaki and the Parthenon, 'the crisis' became and currently remains the new, dominant folkloric image of the country, a popular icon reproduced on the news around the world, a totem and an axiom in the sociopolitical domain but also in humanities' research (see e.g. contributions in Tziovas 2017).

In this context, public institutions responsible for the management of the natural/cultural resources faced insurmountable difficulties. Budget cuts, lack of adequate infrastructure, political instability and the umbrella argument of the lazy Greeks, living beyond their means, supported a peer pressure to 'mobilise untapped resources' (Plantzos 2018; Voudouri 2014). This gave rise to recurring arguments of privatisation on different levels, in different fields and in different processes. However, the narratives of 'how to gain from cultural heritage' are not really systematic, even though empty axioms on synergy, sustainability and lately participatory processes recur in the omnipresent deliberation of culture for tourism.

This deregulatory process instigated by the economic recession, urging for the privatization of the public and common wealth, and the humanitarian crisis that had befallen the citizenship, was met with the emergence of a number of grassroots movements and solidarity collectives that sprang up to ameliorate the hardship the people were going through, organising and delivering social goods (Chatzinakos this volume; Galanos this volume). Among others, one can list food initiatives ('without middlemen' networks, solidarity kitchens, cooperative social groceries; Travlou this volume), education initiatives, solidarity clinics and social pharmacies, (precarious) workers' mutual aid funds and campaigns, housing, legal support, initiatives against water privatization or for immigrants/refugees. This, however, is still a minority of the wide range of goods and processes that were once taken care of by state provisions (De Angelis 2017; Lieros 2016: 350).

This colourful range of initiatives has contributed to the theorization of the commons, their governance and production, through research projects, 


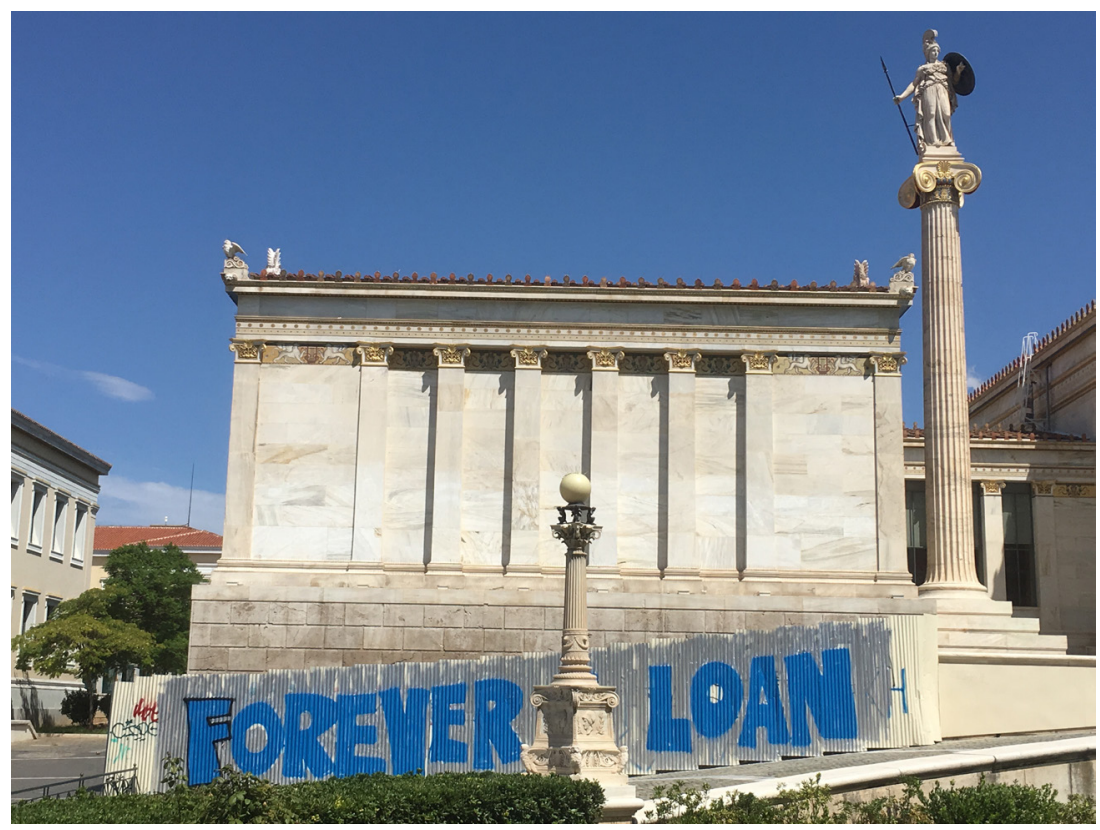

Figure 1: The Academy of Athens (T. Hansen 1859) during debt-crisis demonstrations (Source: author, 2017).

academic publications, workshops and festivals (Papanikolaou 2019). What is more, in recent years a number of government initiatives have emerged, aimed at systematizing the Social and Solidarity Economy framework in Greece (L.4430/2016; L.4605/2019; L.4608/2019), the energy and education commons (L.4513/2018; L.4485/2017) and attempting to establish a developmental framework involving the concept of the commons; it remains to be seen if these will have an impact on society and the economy in the long run.

Thus, the first part of this volume delves into the core of the issue, discussing current considerations of heritage commons; Stelios Lekakis comments on the concept of heritage commons as inferred from his work in Greece and the relevant management context, bringing forward a new theoretical framework for the conceptualisation of cultural heritage, grounded in the tripartite structure of the commons, i.e. resources managed by communities through commoning. Mina Dragouni discusses whether heritage goods can be related to the economic conceptualisation of Common Pool Resources (CPR), proposing novel research tools (economic experiments) to explore collective management alternatives in the field. Despina Catapoti, Ioulia Skounaki and Georgia Gkoumopoulou examine the concept of openness in urban archaeological sites in relation to public / private (open-closed) parameters. They seek answers in the Archaeological Park of Plato's Academy (see also Galanos in this volume) and the Philopappos Hill case studies. 
Part two takes us to a number of different fields, and a mix of academic and opinion papers, addressing current debates from the common's front in Greece. Styles differ significantly, however they all can be considered as 'notes from the field', providing examples of 'commoning' patterns, processes of collaboration and conflicts around property rights and/or institution-creating from unusual but useful perspectives. Nicholas Anastasopoulos discusses the continuum between traditional commons and their digital configurations, along with the social process of coming together to produce, curate and inherit use-valuable resources. Prodromos Tsiavos looks at the limitations and prohibitions imposed by the Greek Archaeological Law in managing representations of heritage material and how that plays out in the digital sphere, where 'regulators' and mainly 'netocrats' (sharing mega-platforms run by private bodies) operate on different rules. On the same note, Marina Markellou \& Petros Moris discuss a contemporary art project and how it attempted to incorporate heritage material in the final product, raising questions about traditional notions of originality and authenticity along with issues concerning the legal framework for the use of heritage elements in digital creations.

Vasso Kanellopoulou looks at the case of seeds, discussing how the current legal provisions hinder the circulation of traditional varieties of seeds - as a CPR - and are intended to protect industrial seeds in the name of commerce regulations. Also, on the matter of food, Penny Travlou discusses the activities of the OneLoveKitchen collective in Athens, considering the transnational context of cultural production and the shifting concept of intangible heritage, that coalesce in acts of commoning. Giorgos Chatzinakos explores the longstanding neighbourhood initiative in Thessaloniki, attempting to provide the physical and immaterial space for communicating, sharing, and eventually commoning. In parallel, Chrysostomos Galanos describes the story of Plato's Academy co-op Café, as a hands-on endeavour in urban commons, along with relevant tools needed in the process; a prototype that was then followed in other cases in Athens and beyond.

Finally, in Part 3, on a more political note, Alexandros Kioupkiolis sets the focus on the horizon, commenting on the lack of strategic thinking in terms of potential political transformation, bringing forward interesting practices from Italy while Dimitris Markopoulos questions the set-up of the discussion on commons in relation to the private and the public when it comes to politics.

\section{Aspirations}

At the end of the rather long session held at the 2015 Dialogues in Archaeology Conference, a colleague raised their hand and posed a somewhat general comment that went along the lines of: 'I don't agree with all of this. Products have always been circulated, people have always paid a price for a service and middlemen got what they were entitled to'. Although panel members had pinpointed the character of the CPRs historically and the processes of sharing and 
commoning as embedded in the history of humanity, I think that the nub of the question remains unanswered; indeed in the framework of normalized capitalism, the market can seem the only legitimate venue to interact with others over resources, in a surveilled, monetized system set to handle all types of transactions, related to material or immaterial goods. It feels somehow natural to be expected to pay for everything.

Social and cultural goods are processed through the same framework, shaped by the same tools and diligently prepared for audit accounting reports. In fact, aggressive neoliberal agendas now claim deeper subordination of vital elements, unexplored niches of people's everyday lives, cultural aspects included.

Attempting to re-consider given 'truths', we need to focus on solid theoretical but also relatable and feasible schemata. It is interesting that the commons have come back to public awareness precisely at a time of global political and social uncertainty and anxiety. The main argument of the commons, reflecting processes of collaboration and sharing, should be considered a political principle, fashioning a new political subjectivity, making it possible to theorise the conditions of collective action, formulate new principles and link dispersed activities towards a new model of governance (Dardot \& Laval 2019: 4). This provides the social and political framework to examine a case study from a holistic approach, uniting economic, ideological, cultural and political points of reference on an alternative basis, rather than the dominant public/private hiatus paradigm.

In the field of heritage, commons theory and practice allow for critical exploration on ontological features of the entities involved, the role of the surrounding stakeholders and the exigent frames for the protection and management, but most importantly open the discussion for further argumentation, frameworks and potential implementation models (institutions) for heritage commons. Discussing heritage within the framework of the contemporary socio-political system of Europe and especially within the dispossessed framework of Greece, allows us to delve further into the strengths, opportunities and potential pitfalls of such an endeavour.

Enveloped in the emerging scene of critical heritage studies, this volume should be considered as an initial step forward, a primary sketch aimed at precipitating a paradigm shift, while at the same time furthering the element of amazement and disbelief that we encounter when we present the possibility of cultural heritage in the realm of the commons.

\section{Acknowledgements}

This volume, which aspires to describe and discuss the boundaries of the emerging field of 'heritage commons', through a focused case study on Greece and from an interdisciplinary perspective, would not have been possible without the generous contributions of the authors, two insightful reviews by Dr. Georgios Alexopoulos (UCL) and Dr. Peter G Gould (University of 
Pennsylvania), the concise proof-editing by Dr. Emmet Marron, the reference list editing by Konstantina Nikolopoulou and the timely arrangements by Ubiquity Press (Imogen Clarke and colleagues). The artwork on the cover was crafted by Ioannis Oikonomakis. Support received from the Faculty of Humanities and Social Sciences, Newcastle University. To support the dissemination of ideas and contribute further to the wider discussions in the field, the volume is published under the Creative Commons BY-NC licence.

\section{Bibliography}

Bauwens, M., Kostakis, V. \& Pazaitis, A. (2019). Peer to peer: The commons manifesto. London, United Kingdom: University of Westminster Press.

Bauwens, M. \& Niaros, V. (2017). Value in the commons economy: Developments in open and contributory value accounting. Chiang Mai, Thailand: Heinrich-Böll-Foundation \& P2P Foundation.

Bekridaki, G. \& Broumas, A. (2016). The Greek society in crisis and in motion: Building the material bases for an alternative society from the bottom up. Retrieved November 20, 2019, from https://papers.ssrn.com/sol3/papers .cfm?abstract_id=2853050.

Benesch, H., Hammami, F., Holmberg, I. \& Uzer, E. (Eds.). (2015). Heritage as common(s) - Commons as heritage. Gothenburg, Sweden: Makadam.

Benkler, Y. \& Nissenbaum, H. (2006). Commons-based peer production and virtue. The Journal of Political Philosophy, 14(4), 394-419.

Bertacchini, E. Saccone D. \& Santagata, W. (2011). Embracing diversity, correcting inequalities: towards a new global governance for the UNESCO World Heritage. International Journal of Cultural Policy, 17 (3), 278-288.

Bloemen, S. \& De Groot, T. (Eds.). (2019). Our commons: Political ideas for a new Europe. Retrieved November 20, 2019, from https://www.commons network.org/ourcommons/.

Bollier, D. (2008). Viral spiral: How the commoners built a digital republic of their own. New York, NY: New Press.

Caffentzis, G. \& Federici. S. (2014). Commons against and beyond capitalism. Community Development Journal, 49(suppl. 1), i92-i105. DOI: https://doi. org/10.1093/cdj/bsu006.

Dardot, P. \& Laval, C. (2019). Common: On revolution in the $21^{\text {st }}$ century. London, United Kingdom: Bloomsbury Academic.

De Angelis, M. (2017). Omnia sunt communia. On the commons and the transformation to postcapitalism. London, United Kingdom: ZED books.

Dellenbaugh, M., Kip, M., Bieniok, M., Müller, A. K. \& Schwegmann, M. (Eds.). (2015). Urban commons: Moving beyond state and market. Berlin, Germany: Birkhäuser.

Erickson, C. (1992). Applied Archaeology and Rural Development: Archaeology's Potential Contribution to the Future. Journal of the Steward Anthropological Society, 20 (1-2): 1-16. 
Federici, S. (2012). Feminism and the politics of the commons. In D. Bollier \& S. Helfrich (Eds.), The wealth of the commons: A world beyond the market \& state (pp. 45-54). Amherst, MA: Levellers Press.

Gibson-Graham, J. K., Cameron, J. \& Healy, S. (2013). Take back the economy: An ethical guide for transforming our communities. Minnesota, MN: University of Minnesota Press.

Gonzalez, P. A. (2014). From a given to a construct: Heritage as a commons. Cultural Studies, 28(3), 359-390. DOI: doi.org/10.1080/09502386.2013 .789067.

Gould, P. G. (2014). A tale of two villages: Institutional structure and sustainable community organizations. Public Archaeology, 13(1-3), 164-177.

Gould, P. G. (2017). Considerations on governing heritage as a commons resource. In P. G. Gould \& K. A. Pyburn (Eds.), Collision or Collaboration. Archaeology Encounters Economic Development (pp. 171-187). Cham, Switzerland: Springer.

Hardin, G. (1968). The tragedy of the commons. Science, 162(3859), 1243-1248. Hardt, M. \& Negri, A. (2012). Declaration. Argo-Navis Author Services.

Harvey, D. (2012). Rebel cities: From the right to the city to the urban revolution. London, United Kingdom: Verso.

Harvey, D. (2016). The ways of the world. London, United Kingdom: Profile books.

Hess, C. (2012). The unfolding of the knowledge commons. St. Anthony's International Review, 8(1), 13-24.

Law 3028/2002. On the protection of antiquities and cultural heritage in general. Retrieved November 20, 2019, from https://www.bsa.ac.uk/wp-content /uploads/2018/11/Archaeological-Law-3028-2002.pdf.

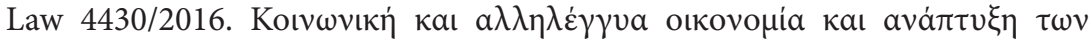

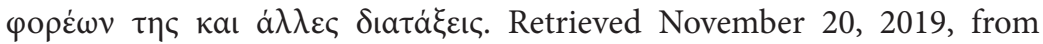
https://www.taxheaven.gr/laws/law/index/law/781.

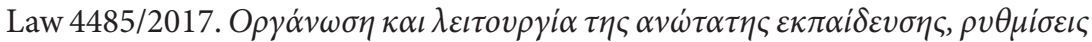
$\gamma \iota \alpha \tau \eta v \dot{\varepsilon} \rho \varepsilon v v \alpha \kappa \alpha \iota \alpha \dot{\lambda} \lambda \varepsilon \varsigma \delta \iota \alpha \tau \dot{\alpha} \xi \varepsilon \iota \varsigma$. Retrieved November 20, 2019, from https://www.taxheaven.gr/laws/law/index/law/829.

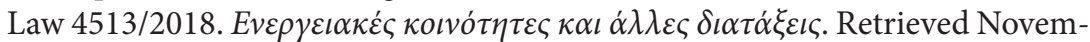
ber 20, 2019, from https://www.taxheaven.gr/laws/law/index/law/859.

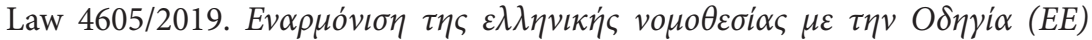

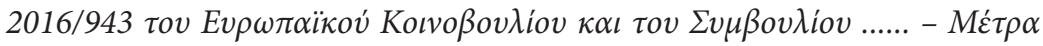

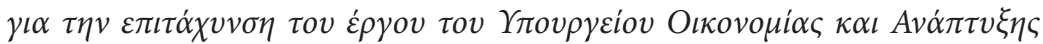

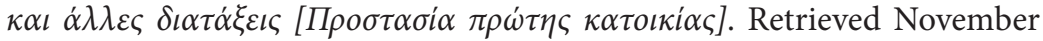
20, 2019, from https://www.taxheaven.gr/laws/law/index/law/923.

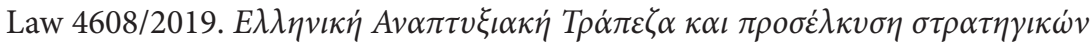
$\varepsilon \pi \varepsilon v \delta \dot{\sigma} \sigma \varepsilon \omega v \kappa \alpha \iota \dot{\alpha} \lambda \lambda \varepsilon \varsigma \delta \iota \alpha \tau \dot{\alpha} \xi \varepsilon \iota \varsigma$. Retrieved November 20, 2019, from https://www.taxheaven.gr/laws/law/index/law/926.

Lekakis, S., Shakya, S. \& Kostakis, V. (2018). Bringing the community back: A case study of the post-earthquake heritage restoration in Kathmandu valley. Sustainability, 10(8), 2978. DOI: https://doi.org/10.3390/su10082798. 


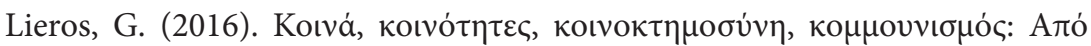

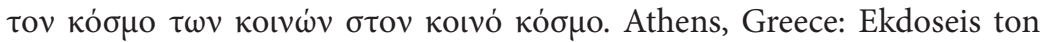
synadelfon.

Linebaugh, P. (2008). The Magna Carta Manifesto: Liberties and commons for all. Berkeley, CA: California University Press.

Olsen, M. (1965). The logic of collective action: Public goods and the theory of groups. Cambridge, MA: Harvard University Press.

Ostrom, E. (1990). Governing the commons: The evolution of institutions for collective action. Cambridge, United Kingdom: Cambridge University Press.

Papadimitropoulos, V. (2017). The politics of the commons: Reform or revolt? Triple C, 15(2), 563-581. DOI: https://doi.org/10.31269/triplec.v15i2.852.

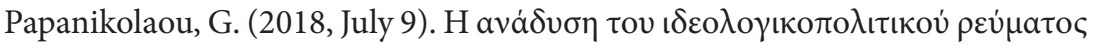

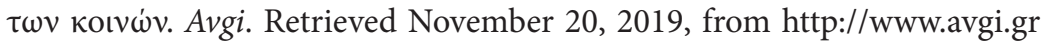
/article/10811/9023370/e-anadyse-tou-ideologikopolitikou-reumatos-ton -koinon.

Plantzos, D. (2018). Crisis, austerity measures and beyond: Archaeology in Greece since the global financial crisis. Archaeological Reports, 64(November), 171-180. DOI: https://doi.org/10.1017/S0570608418000261.

Rodgers, C. P., Straughton, E. A., Winchester, A. J. L. \& Pieraccini, M. (2011). Contested common land: Environmental governance past and present. Abingdon, United Kingdom: Earthscan.

Scharper, S. \& Cunningham, H. (2006). The genetic commons: Resisting the neo-liberal enclosure of life. Social Analysis, 50(3), 195-202. DOI: https:// doi.org/10.3167/015597706780459403.

Tziovas, D. (Ed.). (2017). Greece in crisis: The cultural politics of austerity. London, United Kingdom: I. B. Tauris.

Van Laerhoven, F. \& Ostrom, E. (2007). Traditions and trends in the study of the commons. International Journal of the Commons, 1(1), 3-28. DOI: https://doi.org/10.18352/ijc.76.

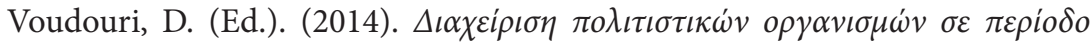

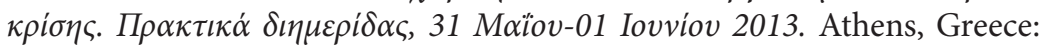
Panteion University.

Zückert, H. (2012). The commons: A historical concept of property rights. In D. Bollier and S. Helfrich (Eds.), The wealth of the commons: A world beyond market and state (pp. 125-131). Amherst, MA: Levellers Press. 
